(c) American Dairy Science Association, 2007.

\title{
Plasma Concentrations of Gut Peptides in Dairy Cattle Increase after Calving
}

\author{
A. E. Relling and C. K. Reynolds ${ }^{1,2}$ \\ Department of Animal Sciences, The Ohio State University, OARDC, Wooster 44691-4096
}

\section{ABSTRACT}

Effects of transition from late gestation to early lactation on plasma concentrations of glucose-dependent insulinotropic polypeptide (GIP), glucagon-like peptide 1-(7-36) amide (GLP-1), and cholecystokinin (CCK) have not been reported in cattle. The objective of the present study was to measure plasma concentrations of GLP-1, GIP, CCK, insulin, glucose, and nonesterified fatty acids in blood plasma obtained from the coccygeal vein of 32 Holstein cows at an average of $11 \mathrm{~d}$ before, and 5,12 , and $19 \mathrm{~d}$ after calving. Feed dry matter intake (DMI) averaged 14.4, 17.7, and $19.9 \mathrm{~kg} / \mathrm{d}$ on d 5,12 , and 19 of lactation, respectively, as milk yield increased (30.6, 36.6, and $39.7 \mathrm{~kg} / \mathrm{d}$, respectively). Plasma concentrations of insulin and glucose were lower postpartum than prepartum, but did not differ among samples collected after calving. In contrast, plasma concentration of gut peptides increased linearly after calving, perhaps as a consequence of increased feed intake and nutrient absorption; however, the increases in plasma concentrations of GIP and GLP-1 as lactation progressed were not associated with increased DMI per se, and likely reflect the endocrine and metabolic adaptations of lactogenesis. In contrast, increased concentration of CCK was related both to increasing days in milk and DMI. By $19 \mathrm{~d}$ postpartum, concentrations of GLP-1, GIP, and CCK increased by 2.3-, 1.8-, and 2.8-fold, respectively, compared with values at $11 \mathrm{~d}$ before calving. Although these peptides have direct and indirect effects that reduce appetite and DMI in other species (including increased insulin secretion), these may be glucose- or insulin-dependent functions, and insulin and glucose concentrations were reduced in early lactation.

Key words: transition, dairy cow, gut peptide

\section{INTRODUCTION}

The transition period from late gestation to early lactation in dairy cows is characterized by an increase

Received June 14, 2006.

Accepted August 21, 2006.

${ }^{1}$ Corresponding author: c.k.reynolds@reading.ac.uk

${ }^{2}$ Current address: School of Agriculture, Policy, and Development, The University of Reading, PO Box 237, Earley Gate, Reading, RG6 $6 \mathrm{AR}, \mathrm{UK}$. in DMI with increasing milk yield after calving. In contrast, in high-yielding cows, the increase in net energy intake that occurs is not enough to meet requirements during the onset of lactation. Early lactation is also characterized by a decrease in plasma insulin concentration that accompanies the decrease in tissue energy balance in early lactation (Ingvartsen and Andersen, 2000). In nonruminants, insulin secretion is increased by glucose-dependent insulinotropic polypeptide (GIP) and glucagon-like peptide 1-(7-36) amide (GLP-1), which are gut hormones secreted by the small intestine in response to luminal nutrient concentrations (McCarthy et al., 1992; Hansen et al., 2004) and act as incretins in nonruminants (Fehmann et al., 1995). Incretins are hormones secreted by the small intestine during the digestive process that enhance insulin secretion by the pancreas to prepare other tissues (i.e., adipose and muscle) for utilization of absorbed nutrients. In addition, GLP-1 and cholecystokinin (CCK) can decrease DMI through effects on hypothalamic receptors and gut motility (Holst, 1997; Druce et al., 2004).

Relatively little is known about the metabolism and function of GIP, GLP-1, and CCK in ruminants. Faulkner and Martin (1997) reported an increase in GIP and GLP-1 concentration in lactating sheep compared with nonlactating sheep. In contrast, concentration of insulin decreased during lactation compared with that during the dry period, indicating a lack of association between GIP or GLP-1 and insulin. In sheep, intracerebroventricular injection of CCK reduces appetite, but the role of CCK in regulating meal size and DMI in ruminants is not certain (Ingvartsen and Andersen, 2000; Benson and Reynolds, 2001). To our knowledge, no reports exist that characterize effects of transition from late gestation to early lactation on circulating concentrations of these gut hormones in cattle. Therefore, our objective was to determine the effect of the transition from late gestation to early lactation on plasma concentrations of GIP, GLP-1, and CCK, as well as plasma concentration of insulin and glucose.

\section{MATERIALS AND METHODS}

\section{Cows, Diets, and Sampling}

Thirty-two Holstein cows assigned to a vitamin C supplementation experiment were sampled for the 
RELLING AND REYNOLDS

Table 1. Formulation of control and vitamin C-supplemented diets

\begin{tabular}{|c|c|c|c|c|}
\hline \multirow[b]{2}{*}{ Ingredient } & \multicolumn{2}{|c|}{ Dry period diet } & \multicolumn{2}{|c|}{ Lactation diet } \\
\hline & Control & Vitamin $\mathrm{C}$ & Control & Vitamin $\mathrm{C}$ \\
\hline Grass hay, long & 360 & 360 & - & - \\
\hline Alfalfa silage & 220 & 220 & 370 & 370 \\
\hline Corn silage & 50 & 50 & 150 & 150 \\
\hline Corn meal & 243 & 237 & 549 & 517 \\
\hline Soybean meal, $44 \% \mathrm{CP}$ & 49.7 & 49.7 & 85.8 & 85.8 \\
\hline Molasses (cane) & 3.0 & 3.0 & - & - \\
\hline Treated soybean meal ${ }^{1}$ & - & - & 383 & 383 \\
\hline Soybean hulls & 38.1 & 38.1 & 172.5 & 172.5 \\
\hline Distillers dried grains & 15.2 & 15.2 & 68.8 & 68.8 \\
\hline Tallow & 4.73 & 4.73 & 21.44 & 21.44 \\
\hline Dicalcium sulfate & 1.33 & 1.33 & 5.99 & 5.99 \\
\hline Limestone & 2.70 & 2.70 & 23.28 & 23.28 \\
\hline Magnesium sulfate & 1.23 & 1.23 & - & - \\
\hline Sodium bicarbonate & 0.85 & 0.85 & 3.87 & 3.87 \\
\hline Magnesium oxide & 1.52 & 1.52 & 1.30 & 1.30 \\
\hline Copper sulfate & 0.04 & 0.04 & 0.08 & 0.08 \\
\hline Zinc oxide & 0.02 & 0.02 & - & - \\
\hline Zinc sulfate & 0.04 & 0.04 & 0.16 & 0.16 \\
\hline Trace mineralized salt ${ }^{2}$ & 3.30 & 3.30 & 9.14 & 9.14 \\
\hline Selenium $(200 \mathrm{mg} / \mathrm{kg}) \mathrm{mix}$ & 2.16 & 2.16 & 2.99 & 2.99 \\
\hline Zinpro $100^{3}$ & 0.17 & 0.17 & 0.08 & 0.08 \\
\hline Vitamin A, 30,000 IU/g & 0.30 & 0.30 & 0.33 & 0.33 \\
\hline Vitamin D, 3,000 IU/g & 0.65 & 0.65 & 0.90 & 0.90 \\
\hline Vitamin E, $44 \mathrm{IU} / \mathrm{g}$ & 1.95 & 1.95 & 1.30 & 1.30 \\
\hline Vitamin $\vec{C}(350 \mathrm{~g} / \mathrm{kg}) \operatorname{mix}$ & - & 6.12 & - & 31.70 \\
\hline
\end{tabular}

${ }^{1}$ SurePro, Land O'Lakes, St. Paul, MN.

${ }^{2}$ Containing 3,500 ppm Zn; 2800 ppm Mn; 400 ppm Cu; and 70 ppm I.

${ }^{3}$ Zinc $(100 \mathrm{mg} / \mathrm{kg})$ and methionine $(200 \mathrm{mg} / \mathrm{kg})$ complex; Zinpro, Eden Prairie, MN.

present study. Cows were selected on the basis of calving date and assigned to either of 2 dietary treatments, with or without supplemental vitamin $\mathrm{C}$, for the duration of the study. Cows were fed late-gestation rations, differing in vitamin $\mathrm{C}$ concentration (Table 1), to meet or exceed requirements for other nutrients based on NRC (2001) recommendations while housed in group pens in a free-stall barn. Treatment diets were fed beginning at dry off $60 \mathrm{~d}$ before expected calving date. On d 10 before their expected calving date, cows were moved to individual box stalls for calving. Beginning 1 to $2 \mathrm{~d}$ before calving, long alfalfa hay was fed ad libitum. Feed intake was not measured before calving. After calving, a mixed lactation ration with or without the addition of vitamin $\mathrm{C}$ (Table 1 ) was fed for ad libitum intake. After $2 \mathrm{~d}$ recovery from calving, cows were moved to tie-stalls for the remainder of the study. Cows had continuous access to water throughout the study.

When cows were in tie-stalls, they were fed once daily at $0300 \mathrm{~h}$. Milk yield and DMI were measured daily, and milk composition was measured weekly as described by Beckman and Weiss (2005).

Blood samples were collected at $0700 \mathrm{~h}$ by venipuncture of the coccygeal vein an average $( \pm$ SEM) of $11 \pm$ $1.2 \mathrm{~d}$ before expected calving date and $5 \pm 0.4,12 \pm 0.4$, and $19 \pm 0.4 \mathrm{~d}$ after calving. Blood was immediately transferred to tubes containing disodium EDTA and benzamidine $\mathrm{HCl}(1.6$ and $4.7 \mathrm{mg} / \mathrm{mL}$, respectively; Reynolds et al., 1989) and placed on ice. After centrifugation for $30 \mathrm{~min}$ at $1,800 \times \mathrm{g}$ and $4^{\circ} \mathrm{C}$, plasma was separated into aliquots for each assay and then stored in polypropylene tubes at $-85^{\circ} \mathrm{C}$ until analyzed.

\section{Plasma Analyses}

Concentrations of hormones in plasma were measured using double-antibody RIA. Insulin was measured using an equilibrium assay described by Reynolds et al. (1989). Minimum sensitivity of the insulin assay (the lowest standard concentration at which binding was $90 \%$ of binding for the zero standard) was 0.003 $\mathrm{pmol} /$ tube. Concentration of GLP-1 was measured using the disequilibrium assay described by Benson and Reynolds (2001); minimum sensitivity of the GLP-1 assay was $0.001 \mathrm{pmol} / \mathrm{tube}$. The GIP assay used was based on the disequilibrium assay described by Morgan et al. (1978). The assay used the insulin assay buffer and 24- and 48-h incubations before additions of labeled GIP and a second antibody, respectively. The rabbit antihuman antibody used (Rab-027-02, Phoenix Pharmaceuticals, Inc., Belmont, CA) was reported to have $100 \%$ cross-reactivity with porcine GIP. Displacement 
of labeled human GIP (T-027-02, Phoenix Pharmaceuticals, Inc.) binding by serial additions of bovine plasma was parallel to the displacement by serial additions of porcine GIP standards (Sigma-Aldrich, St. Louis, MO). Minimum sensitivity of the GIP assay was $0.05 \mathrm{pmol} /$ tube. Concentration of CCK was measured in plasma using a commercial disequilibrium CCK-8 assay (EuroDiagnostica, Malmö, Sweden) as described previously (Benson and Reynolds, 2001). Plasma (500 $\mu \mathrm{L}$ ) was extracted with $96 \%$ (vol/vol) ethanol $(1 \mathrm{~mL})$, and then centrifuged at $1,700 \times g$ for $15 \mathrm{~min}$ at $4^{\circ} \mathrm{C}$. The supernatant was decanted to another tube and evaporated in a freeze drier. Minimum sensitivity of the CCK assay was $0.0006 \mathrm{pmol}$ per tube. All samples were analyzed in 1 assay, and the intraassay coefficients of variation were $<21 \%$ for insulin, $<12 \%$ for GIP and GLP-1, and $<10 \%$ for CCK. Plasma concentration of glucose was measured using a commercial colorimetric assay (Trinder \#1070, Stanbio Laboratory, Boerne, TX), and plasma NEFA concentration was measured as described by Johnson and Peters (1993).

\section{Statistical Analyses}

Data were analyzed statistically as repeated measures within cow (random effect) over time (fixed effect) using the MIXED model procedure of SAS (Version 8; SAS Inst. Inc., Cary, NC). The variance components covariance structure, which gave the best fit of the structures compared for each variable. Because of the cost of the CCK assay, only plasma samples from cows without missing observations $(n=26)$ were analyzed for CCK. To account for any nonhomogeneous variance for nutrient and hormone concentrations as lactation progressed (Figures 1 and 2), day was included in the model as a group effect. The group effect was removed from the model used to analyze glucose and insulin concentrations because covariance parameter estimates for group were similar and the null model likelihood test was not significant $(P>0.20)$. Contrasts were used to test effects of transition (d -11 vs. $d 5,12$, and 19) and linear or quadratic effects of day of lactation. In a preliminary statistical analysis of the data, vitamin $\mathrm{C}$ and vitamin $\mathrm{C}$ by time interaction had no effect on any of the variables measured, and so the main effect of vitamin $\mathrm{C}$ was dropped from the statistical model for the data analysis reported in the present paper.

Regression of DMI on actual DIM using the regression procedure of SAS was significant $(P<0.001)$, but the correlation coefficient for the relationship was only 0.17 . Therefore, plasma nutrient and hormone concentrations after calving were analyzed using the MIXED model procedure of SAS and a model testing effects of DMI and DIM (actual day relative to calving; Figures
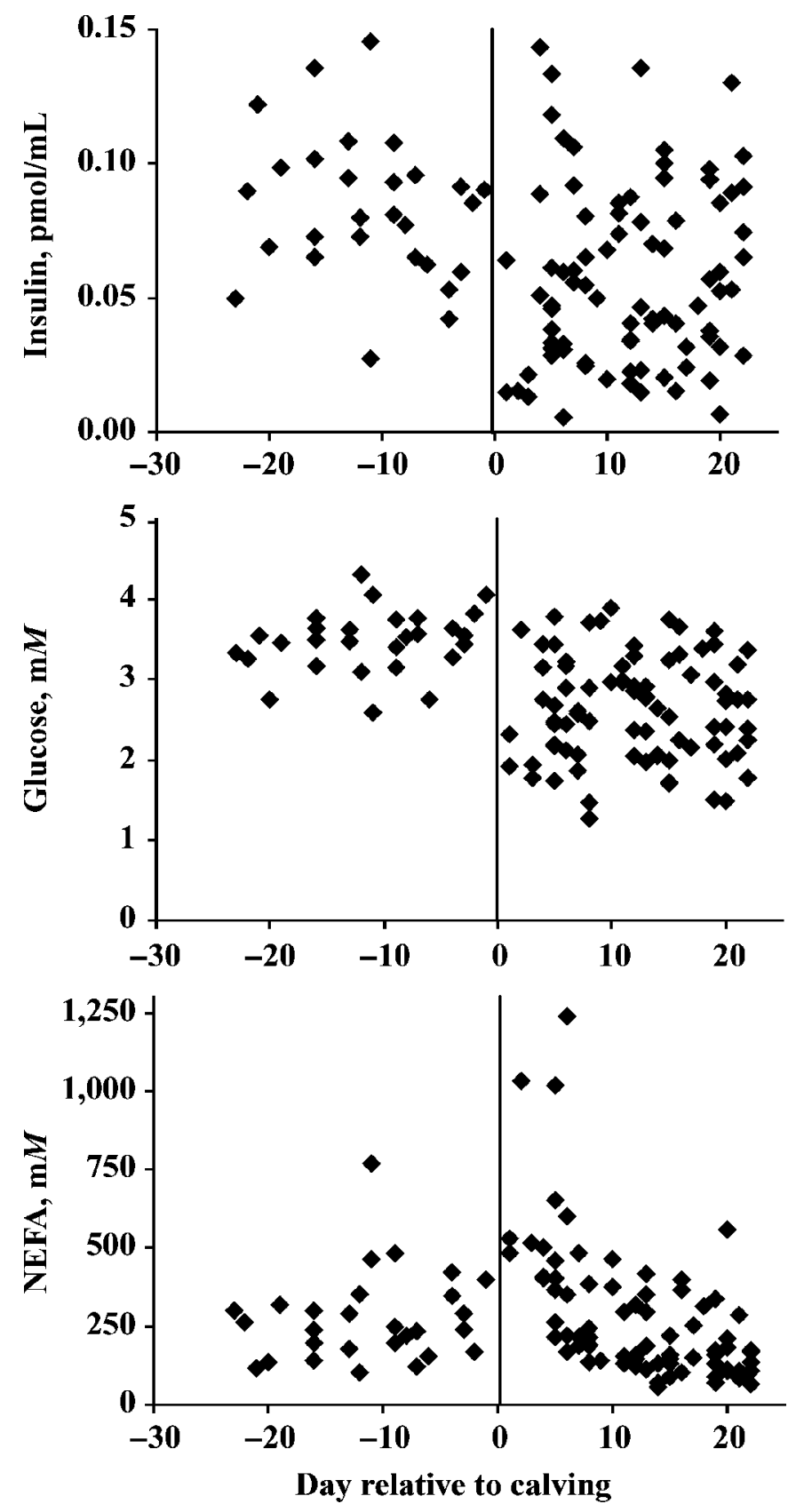

Figure 1. Plasma concentrations of insulin, glucose, and NEFA in transition dairy cows.

1 and 2) as independent continuous variables with the variance components covariance structure and cow as the subject. To account for nonhomogeneous variance, the data were divided into quintiles based on actual DIM and assigned a quintile number that was included in the analysis as a group effect for analysis of NEFA, GLP-1, GIP, and CCK concentrations. The quintile group effect was not significant in the analysis of glucose and insulin concentration $(P=0.77$ and 0.66 , re- 

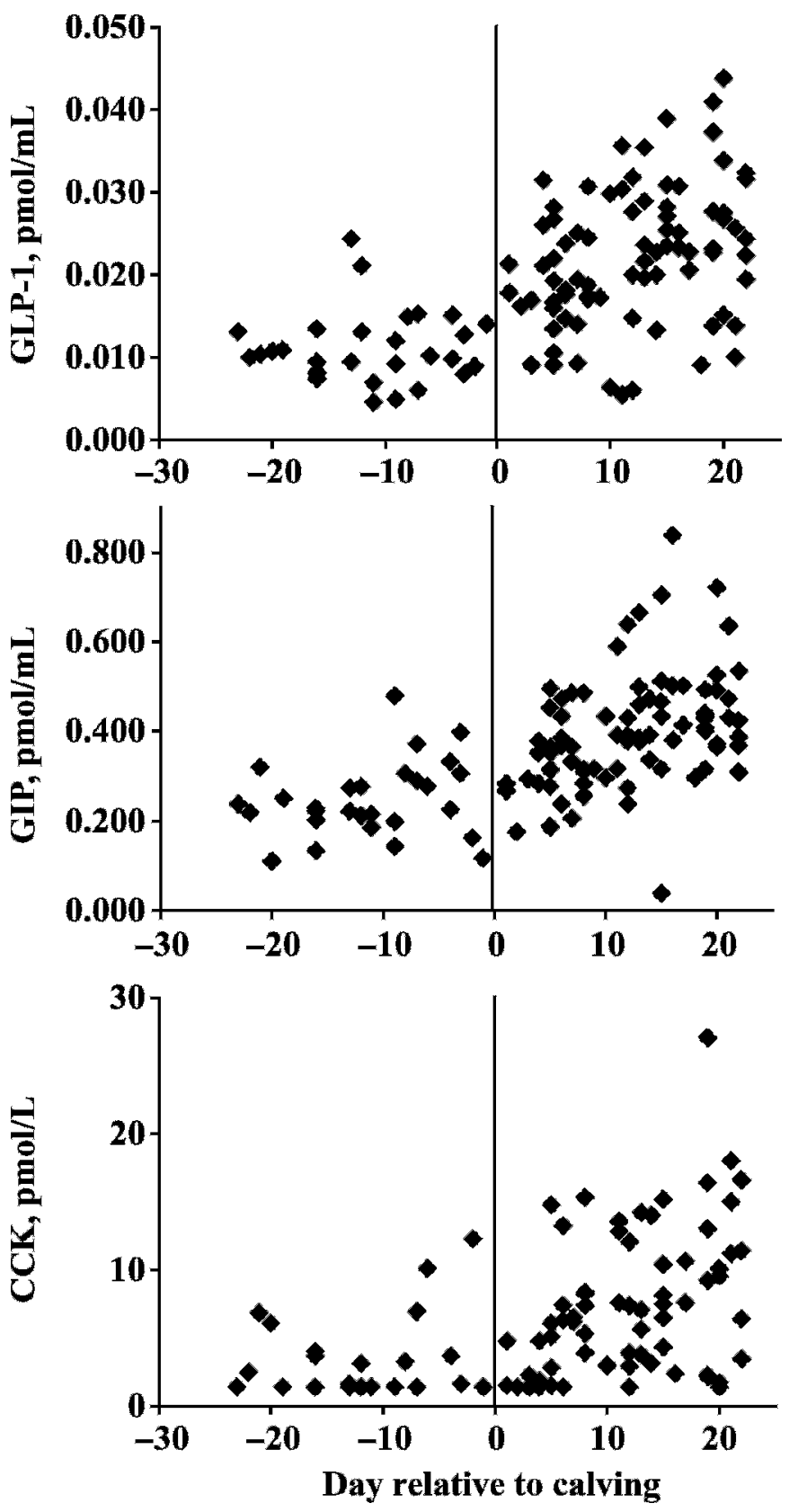

Figure 2. Plasma concentrations of glucagon-like peptide-1-(7-36) amide (GLP-1), glucose-dependent insulinotropic polypeptide (GIP), and cholecystokinin (CCK) in transition dairy cows.

spectively), and therefore was dropped from the model used for their analyses.

\section{RESULTS AND DISCUSSION}

Milk yield and DMI increased linearly $(P<0.001)$ after parturition (Table 2). Although DMI during late gestation was not measured individually, based on BW, diet composition, and the equations of NRC (2001), we estimated that DMI was approximately $12.3 \mathrm{~kg}$ at 11 $\mathrm{d}$ before calving. Plasma glucose and insulin concentrations decreased $(P<0.001)$ from late gestation to early lactation (Table 2), but did not differ across measurements on d 5, 12, and 19 after calving. In contrast, GIP, GLP-1, and CCK increased after calving $(P<0.001)$ and continued to increase linearly $(P \leq 0.02)$ as lactation progressed (Table 2). Plasma concentration of NEFA increased $(P<0.001)$ on $\mathrm{d} 5$ after calving and then linearly decreased $(P<0.001)$ as lactation progressed (Table 2).

Although DMI increased $(P<0.001)$ with successive samplings after calving (Table 2), the response varied among cows. Analysis of effects of DMI and actual DIM on plasma concentrations of nutrients and hormones was conducted to assess the extent that changes in plasma hormone and nutrient concentration as lactation progressed were associated with changes in DMI vs. DIM. The increase in plasma concentration of GLP1 and GIP after calving (Figure 2) was related to increasing $(P<0.003)$ DIM, but not DMI per se (Table $3)$. In contrast, both DMI $(P<0.06)$ and DIM $(P<0.07)$ were related to plasma CCK concentration (Figure 2) during the postpartum period (Table 3 ). Plasma concentration of glucose (Figure 1) was related to DMI $(P<$ 0.02 ), but not DIM (Table 3 ).

As far as we are aware, changes in plasma concentrations of gut peptides during the transition from late gestation to early lactation in dairy cattle have not been previously reported. We observed an increase in plasma concentrations of GIP, GLP-1, and CCK during early lactation that coincided with an increase in feed intake and a decrease in plasma glucose and insulin concentration. This increase in GIP, GLP-1, and CCK concentrations could be because of an increase in gut tissue mass that would be expected with increased DMI in early lactation (Gibb et al., 1992; Reynolds et al., 2004), as well as effects of increased nutrient absorption on the release of these peptides into blood. However, increases in plasma concentration of GIP and GLP-1 as lactation progressed were not related to changes in DMI, and plasma CCK concentration was positively related to both DMI and DIM. In contrast, plasma glucose was related to DMI, but not actual DIM. The positive relationship between DMI and plasma glucose concentration may reflect differences between nutrient supply for glucose absorption and synthesis relative to the demands of lactation. This analysis of our data indicates that for these gut peptides, and especially for GLP1 and GIP, regulation of their plasma concentrations includes factors additional to the amounts of feed consumed and nutrients absorbed. Although the increases in gut peptide concentration we observed after calving may have been attributable in part to the change in 
Table 2. Milk yield, DMI, and plasma concentrations of glucose, NEFA, insulin, glucose-dependent insulinotropic polypeptide (GIP), glucagon-like peptide-1-(7-36) amide (GLP-1), and cholecystokinin (CCK) in dairy cows during late gestation and early lactation

\begin{tabular}{|c|c|c|c|c|c|c|c|c|c|}
\hline \multirow[b]{2}{*}{ Item } & \multicolumn{4}{|c|}{ Average day relative to calving } & \multirow[b]{2}{*}{$\mathrm{SEM}^{1}$} & \multirow[b]{2}{*}{$P^{2}$} & \multicolumn{3}{|c|}{$P^{3}$} \\
\hline & -11 & 5 & 12 & 19 & & & Transition & Linear & Quadratic \\
\hline Milk yield, kg/d & - & 30.6 & 36.6 & 39.7 & 1.5 & 0.001 & - & 0.001 & 0.225 \\
\hline DMI, kg/d & $\mathrm{ND}^{4}$ & 15.2 & 17.7 & 19.9 & 0.60 & 0.001 & - & 0.001 & 0.569 \\
\hline Glucose, $\mathrm{m} M$, & 3.54 & 2.61 & 2.73 & 2.60 & 0.12 & 0.001 & 0.001 & 0.885 & 0.353 \\
\hline NEFA, $\mu M$ & 285 & 436 & 239 & 187 & 46 & 0.001 & 0.941 & 0.001 & 0.117 \\
\hline Insulin, $\mathrm{p} M$ & 84.0 & 55.8 & 56.6 & 60.0 & 6.3 & 0.002 & 0.001 & 0.722 & 0.947 \\
\hline GIP, $\mathrm{p} M$ & 254 & 332 & 431 & 451 & 26 & 0.001 & 0.001 & 0.001 & 0.201 \\
\hline GLP-1, pM & 11.2 & 18.9 & 22.9 & 25.3 & 2.6 & 0.001 & 0.001 & 0.003 & 0.693 \\
\hline CCK, $\mathrm{pM}$ & 3.5 & 5.7 & 7.7 & 9.4 & 1.2 & 0.001 & 0.001 & 0.014 & 0.767 \\
\hline
\end{tabular}

\footnotetext{
${ }^{1}$ The SEM for the mean with the most variance is reported.

${ }^{2}$ Probability corresponding to the hypothesis of no overall effect of day relative to calving.

${ }^{3}$ Probability for contrasts testing the effects of transition (d -11 vs. $\left.5,12,19\right)$ and linear or quadratic effects of day of lactation.

${ }^{4} \mathrm{ND}=$ Not determined.
}

ration composition (e.g., fat, $\mathrm{ME}$, and protein concentration), numerous factors in addition to feed intake and nutrient supply such as growth hormone (Shulman, 2000) regulate gut development and thus may affect gut peptide synthesis and secretion. Both GIP and GLP1 are members of the pituitary adenylate cyclase-activating polypeptide/glucagon "superfamily" of 9 peptides, including growth hormone-releasing hormone, with related structure, distribution, receptors, function, and regulation (Sherwood et al., 2000). As for other aspects of the metabolic and endocrine adaptation to lactation (Ingvartsen and Andersen, 2000), the regulation of gut peptide metabolism and function also must occur at multiple levels and in a coordinated manner.

The increase in DMI observed after calving accompanied increased milk yield and a decrease in plasma glucose and insulin concentrations. Ingvartsen and Andersen (2000) suggested that the decreased insulin and glucose concentrations that accompany the increased demand for glucose for milk synthesis in early lactation might promote greater appetite and DMI. In addition, decreased insulin sensitivity (Ingvartsen and Andersen, 2000) might contribute to greater DMI during early lactation.
Although GLP-1 is a hypophagic peptide in nonruminants (Druce et al., 2004), an effect of GLP-1 on DMI in ruminants has not been reported. The present data indicate that increased plasma GLP-1 concentration does not prevent increased DMI in early lactating dairy cows. Dairy cows, however, may be refractory to effects of GLP-1 on intake in early lactation because of decreased insulin and glucose concentrations. In addition, the increase in peripheral plasma GLP-1 concentration measured may not have been large enough to affect DMI in the present study. Similar increases in the plasma concentration of GLP-1, however, have been associated with reduced DMI in mid-lactation dairy cows receiving postruminal infusions of oil, albeit at greater basal GLP-1 concentrations (Benson and Reynolds, 2001; Litherland et al., 2005). Although CCK also is implicated in the regulation of DMI (Ingvartsen and Andersen, 2000; Druce et al., 2004), the increase in plasma CCK concentration observed in early lactation could be more important for the regulation of intestinal digestion through effects on exocrine pancreatic secretions (Tachibana et al., 1995).

The increase in plasma concentration of GIP and GLP-1 observed in early lactation was associated with

Table 3. Solutions for effects of DMI and actual DIM on plasma concentrations of glucose, NEFA, insulin, glucagon-like peptide-1-(7-36) amide (GLP-1), glucose-dependent insulinotropic polypeptide (GIP), and cholecystokinin (CCK) in dairy cows during late gestation and early lactation

\begin{tabular}{|c|c|c|c|c|c|}
\hline & \multicolumn{3}{|c|}{ Estimate $\pm \mathrm{SE}$} & \multicolumn{2}{|c|}{$P$} \\
\hline & Intercept & DMI & DIM & DMI & DIM \\
\hline Glucose, $\mathrm{m} M$ & $2.04 \pm 0.31$ & $0.05 \pm 0.02$ & $-0.02 \pm 0.01$ & 0.019 & 0.225 \\
\hline NEFA, $m M$ & $399.1 \pm 76.4$ & $1.68 \pm 3.93$ & $-13.7 \pm 3.62$ & 0.672 & 0.001 \\
\hline Insulin, $\mathrm{p} M$ & $48.0 \pm 17.1$ & $0.36 \pm 1.06$ & $0.28 \pm 0.73$ & 0.737 & 0.701 \\
\hline GIP, $\mathrm{p} M$ & $279.1 \pm 53.2$ & $0.66 \pm 3.45$ & $8.29 \pm 2.11$ & 0.850 & 0.001 \\
\hline GLP-1, $\mathrm{p} M$ & $16.73 \pm 3.75$ & $-0.06 \pm 0.24$ & $0.52 \pm 0.16$ & 0.816 & 0.003 \\
\hline $\mathrm{CCK}, \mathrm{p} M$ & $-2.01 \pm 2.99$ & $0.38 \pm 0.20$ & $0.23 \pm 0.12$ & 0.056 & 0.070 \\
\hline
\end{tabular}


decreased plasma insulin concentration. Similar results were reported in sheep (Faulkner and Martin, 1997). Based on previous work in sheep (Faulkner and Martin, 1999), stimulation of insulin secretion by increased GIP and GLP-1 concentrations may require greater plasma glucose concentrations than observed in the present study ( $3 \mathrm{~m} M$ or less). In nonruminants, a threshold plasma glucose concentration for the incretin effect of these peptides on insulin secretion has been proposed to be at least $4.5 \mathrm{mM}$ (Holst, 1997).

As reported previously for cows in early lactation (Ingvartsen and Andersen, 2000), plasma NEFA concentration increased $(P<0.001)$ on $d 5$ after calving in our study and then declined to concentrations similar to or less than those on $\mathrm{d} 11$ before calving. Increased plasma concentration of NEFA in the first week of lactation may be because of increased concentration of somatotropin and negative tissue energy balance. Although GIP has lipogenic activity in ruminants (Faulkner and Martin, 1999), the extent to which GIP affects adipose metabolism in early lactation dairy cows is not known.

In conclusion, plasma concentrations of GLP-1, GIP, and CCK increased along with DMI and milk yield after calving in dairy cows. These increases may partially reflect effects of increased nutrient absorption or gut mass. Increases in plasma GLP-1 and GIP as lactation progressed, however, were not associated with increased DMI per se, and likely reflect the endocrine and metabolic adaptations of the rising phase of lactation. Although these peptides have direct and indirect effects that reduce appetite and DMI in other species, including increased insulin secretion, these functions may be glucose-dependent, insulin-dependent, or both. Insulin and glucose concentrations were reduced in early lactation. It may also be that these gut peptides "fine-tune" nutrient metabolism in early lactation through anabolic effects on adipose or perhaps mammary gland metabolism. More research is needed to understand the biology and function of these gut peptides in ruminants.

\section{ACKNOWLEDGMENTS}

We thank J. Hogan and W. Weiss for use of cows and samples from their experiment, L. Winkelman, D. Wyatt, and V. Cannon for technical assistance, and W. Weiss and N. St-Pierre for advice on statistical analysis of the data. A. E. Relling was supported by grants provided by Bunge y Born Foundation and The Fulbright Foundation. Salaries and research support provided by State and Federal funds appropriated to the Ohio Agricultural Research and Development Center, The Ohio State University (Manuscript no. 5-06AS).

\section{REFERENCES}

Beckman, J. L., and W. P. Weiss. 2005. Nutrient digestibility of diets with different fiber to starch ratios when fed to lactating dairy cows. J. Dairy Sci. 88:1015-1023.

Benson, J. A., and C. K. Reynolds. 2001. Effects of abomasal infusion of long-chain fatty acids on splanchnic metabolism of pancreatic and gut hormones in lactating dairy cows. J. Dairy Sci. 84:1488-1500.

Druce, M. R., C. J. Small, and S. R. Bloom. 2004. Minireview: Gut peptides regulating satiety. Endocrinology 145:2660-2665.

Faulkner, A., and P. A. Martin. 1997. The concentrations of some gut polypeptides are elevated during lactation in ruminants. Comp. Biochem. Physiol. B Biochem. Mol. Biol. 118:563-568.

Faulkner, A., and P. A. Martin. 1999. Insulin secretion and intestinal peptides during lactation in sheep. J. Dairy Res. 66:45-52.

Fehmann, H. C., R. Goke, and B. Goke. 1995. Cell and molecular biology of the incretin hormones glucagon-like peptide-I and glucose-dependent insulin releasing polypeptide. Endocr. Rev. 16:390-410.

Gibb, M. J., W. E. Ivings, M. S. Dhanoa, and J. D. Sutton. 1992. Changes in body components of autumn-calving HolsteinFriesian cows over the first 29 weeks of lactation. Anim. Prod. 55:339-360.

Hansen, L., B. Hartmann, H. Mineo, and J. J. Holst. 2004. Glucagonlike peptide-1 secretion is influenced by perfusate glucose concentration and by a feedback mechanism involving somatostatin in isolated perfused porcine ileum. Regul. Pept. 118:11-18.

Holst, J. J. 1997. Enteroglucagon. Annu. Rev. Physiol. 59:257-271.

Ingvartsen, K. L., and J. B. Andersen. 2000. Integration of metabolism and intake regulation: A review focusing on periparturient animals. J. Dairy Sci. 83:1573-1597.

Johnson, M. M., and J. P. Peters. 1993. Technical note: An improved method to quantify nonesterified fatty acids in bovine plasma. J. Anim. Sci. 71:753-756.

Litherland, N. B., S. Thire, A. D. Beaulieu, C. K. Reynolds, J. A. Benson, and J. K. Drackley. 2005. Dry matter intake is decreased more by abomasal infusion of unsaturated free fatty acids than by unsaturated triglycerides. J. Dairy Sci. 88:632-643.

McCarthy, J. P., A. Faulkner, P. A. Martin, and D. J. Flint. 1992. Changes in the plasma concentration of gastric inhibitory polypeptide and other metabolites in response to feeding in sheep. J. Endocrinol. 134:235-240.

Morgan, L. M., B. A. Morris, and V. Marks. 1978. Radioimmunoassay of gastric inhibitory polypeptide. Ann. Clin. Biochem. 15:172-177.

NRC. 2001. Nutrient Requirements of Dairy Cattle. 7th rev. ed. Natl. Acad. Sci., Washington, DC.

Reynolds, C. K., B. Durst, B. Lupoli, D. J. Humphries, and D. E. Beever. 2004. Visceral tissue mass and rumen volume in dairy cows during the transition from late gestation to early lactation. J. Dairy Sci. 87:961-971.

Reynolds, C. K., G. B. Huntington, T. H. Elsasser, H. F. Tyrrell, and P. J. Reynolds. 1989. Net metabolism of hormones by portaldrained viscera and liver of lactating Holstein cows. J. Dairy Sci. 72:1459-1468.

Sherwood, N. M., S. L. Krueckl, and J. E. McRory. 2000. The origin and function of the pituitary adenylate cyclase-activating polypeptide (PACAP)/glucagon superfamily. Endocr. Rev. 21:619670.

Shulman, D. I. 2000. Gastrointestinal effects of growth hormone. Endocrine 12:147-152.

Tachibana, S., T. Onaga, H. Mineo, and S. Kato. 1995. Role of endogenous CCK in regulation of interdigestive pancreatic exocrine secretion in sheep (Ovis aries). Comp. Biochem. Physiol. A Physiol. 112:103-109. 